\title{
The efficacy of life skill training on mother,s coping skill and children,s oppositional difiant disorder symptoms in military family
}

\begin{abstract}
Background and Objective: Child behavior problem is a one of the major issue in parenting and its effect on child and parent relationship is noticble. This study aims at investigating the the efficacy of life skill training on mother,s coping skill and children,s oppositional difiant disorder symptoms in military family.

Material and Methods: This is a quasi-experimental study with a control group conducted on 6-8 years children with oppositional difiant disorder with clinical interview in DSM-5, whoes fathers work at military force in 2018. From the abovementioned population, 40 mothers of this studnets have been selected through available non-random sampling. The data-gathering tools were a demographic questionnaire, Child Symptpm Inventory, Lazarus Coping Style Questionneir in pre-test and post-test. Life skill intervention was performed based on the results of the pre-test in the intervention group in 8 sessions of 45 minutes. The collected data were analyzed using SPSS 18, independent t-test, ANCOA, MANCOVA.

Results: The results of this study showed that the mean score of coping style (searching support, responsibility, problem solving, again positeve apparasial), as well as the children,s oppositional difiant scores were significantly different from that of the control group's after educational intervention $(P<0.001)$, which confirms the effect of life skill traning on the child and parents.

Conclusion: According to the results of this research, life skill traning leads to the development of positive coping skills in mothers with their children and this program in child behvior problem has positive affect. Therefore, the researchers recommend life skill traning methods on child and parent problems.

Keywords: life skill, coping skill, oppositional difiant disorder

Paper Type: Research Article.
\end{abstract}

Citation (Vancouver): Zeinali Sh, Rsotami H. The efficacy of life skill training on mother,s coping skill and children,s oppositional difiant disorder symptoms in military family.. Iran J Health Educ Health Promot. Spring 2020;8(2): 118-128. [Persian]x

- Citation (APA): Zeinali Sh., Rsotami H. The efficacy of life skill training on mother,s coping skill and children,s oppositional difiant disorder symptoms in military family. (Summer 2020). Conc... . Iranian Journal of Health Education \& Health Promotion., 8(2), 118-128. [Persian]

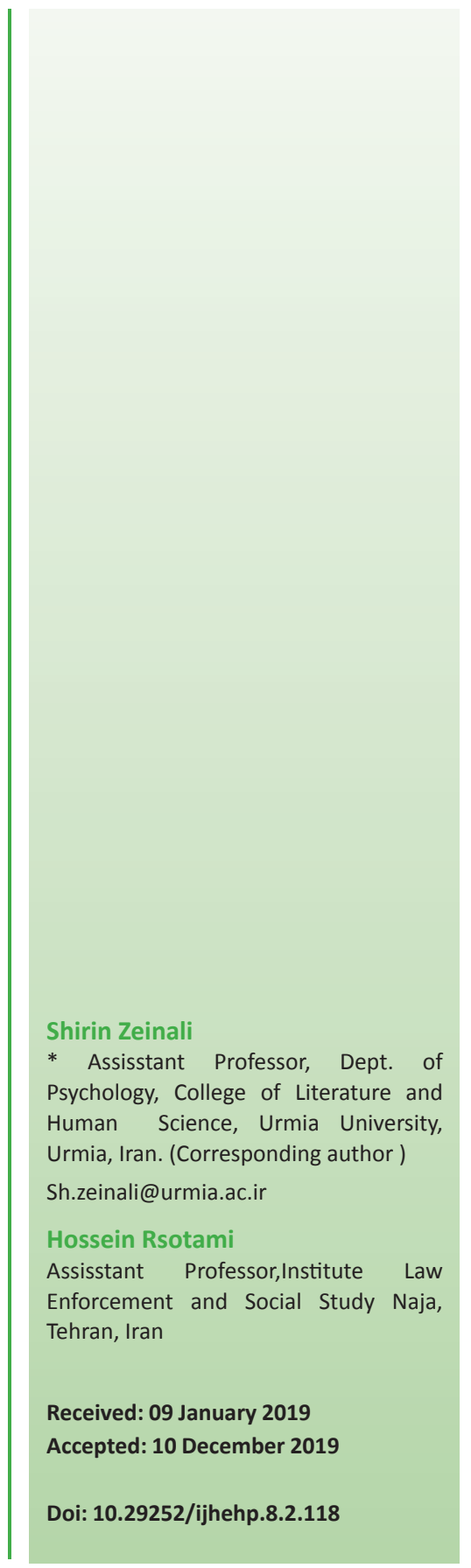




\section{اثربخشى آموزش مهارتهاى زندكى بر مهارتهاى مقابلهاى مادران وعلائم اختلال بهىاعتنايى}

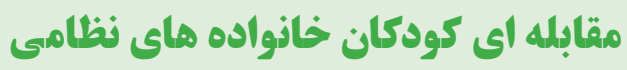

شيرين زينالى

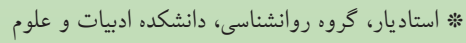

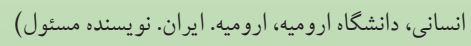
sh.zeinali@urmia.ac.ir

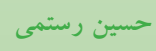

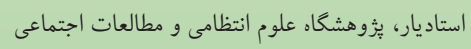

$$
\text { ناجا، تهران، ايران }
$$

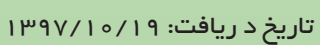

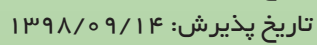

\section{جكيده}

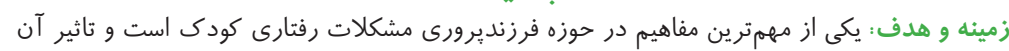

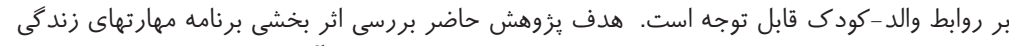

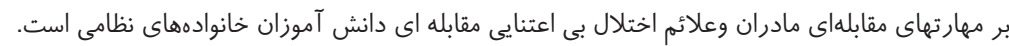

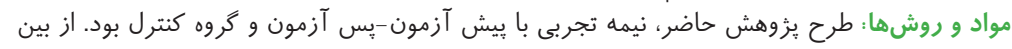

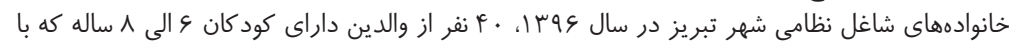

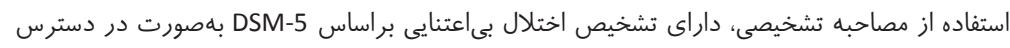

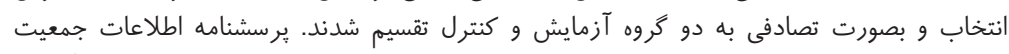

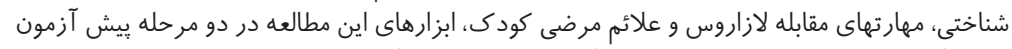

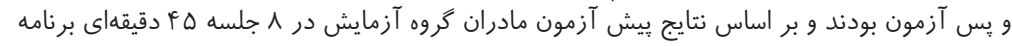

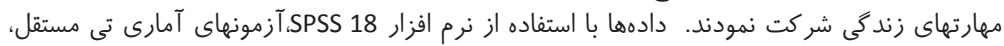

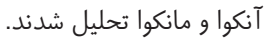

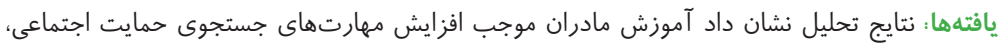

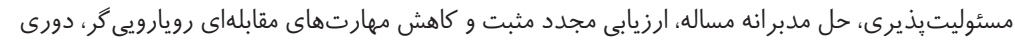

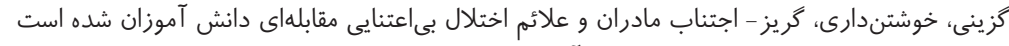

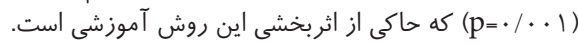

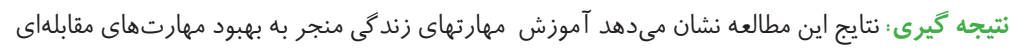

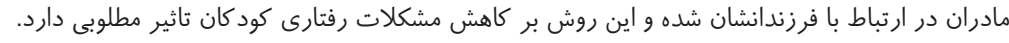

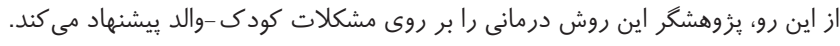

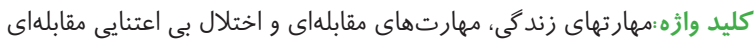
نوع مقاله : مطالعه يُزوهشى.

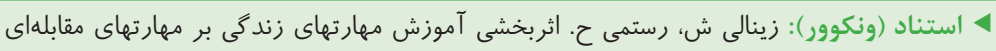

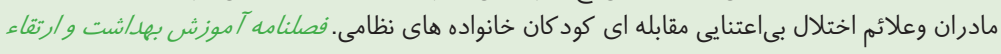

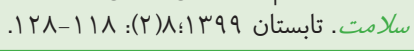

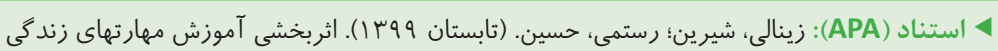

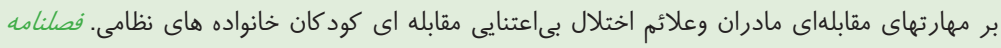

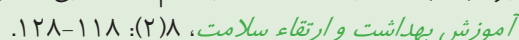


مقابلهاى را به سه نوع تكليف محور، هيجانى و اجتنابى تقسيم نمودهاند. در سبك مقابلهاى تكليف محور هدف تغيير موقعيت تنيدگىزا است. در سبك مقابله هيجانى فرد تلاش مى كند تا بِاسخ خود را به موقعيتهاى تنش زا تغيير دهد و سبك اجتنابى با فرار

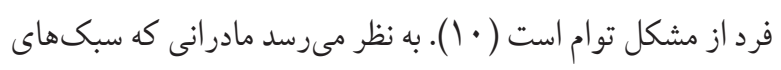

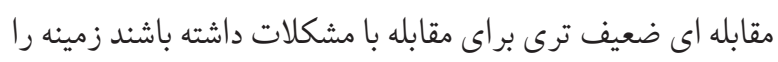

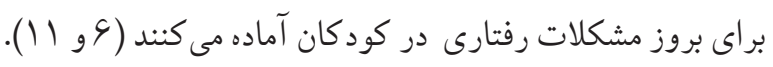

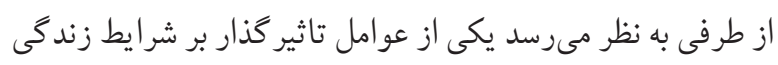

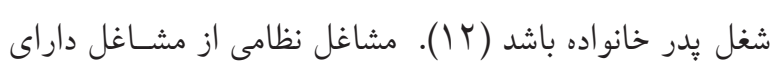

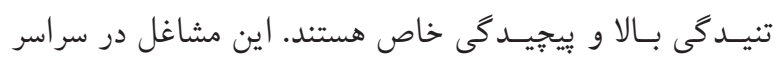

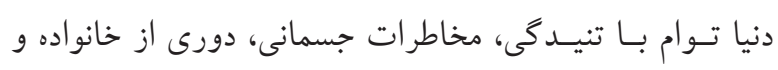

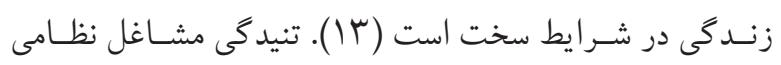

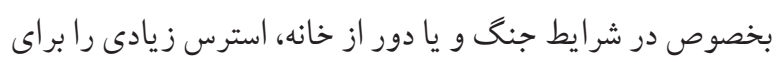

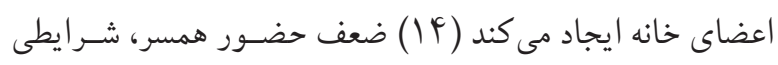

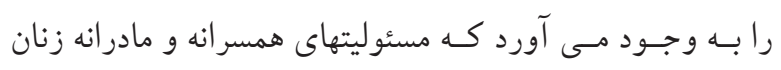

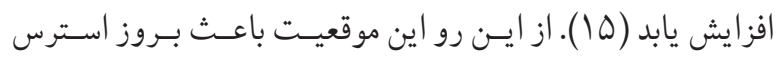

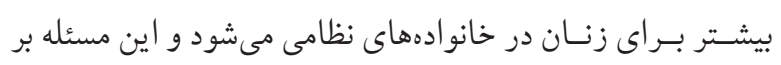
مشكلات رفتارى كود كان مى افزايد (19).

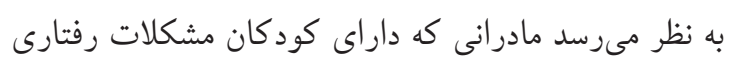
برونى سازى هستند نياز به آموزش در زمينه برخى مهار تهاى رفتارى دئ دارى

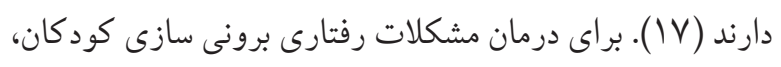
راهبردهاى درمانى متعددى از جمله دارو درمانى، سبكهاى فرزند

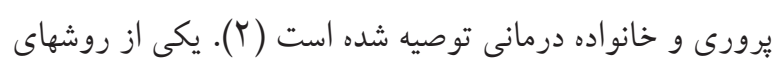

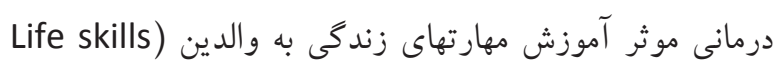

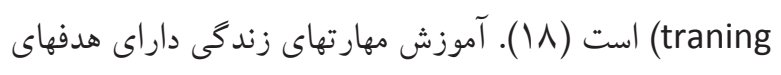

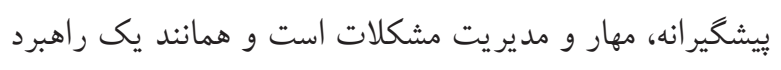

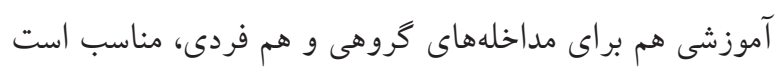

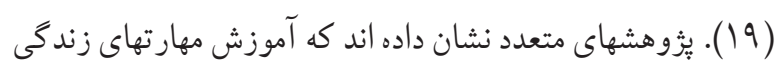
در زمينه هاى افزايش سلامت روانى و جسمانى، تقويت ارتباط بين

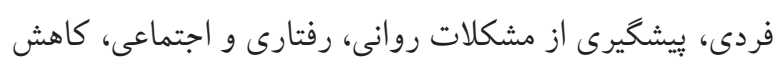
اضطراب و افسردگى و كاهش افت تحصيلى مؤثر بوده است ( • ().
اختلال بى اعتنايى مقابلهاى (oppositional difiant disorder) الكويى از منفى گرايى، لجبازى، بى اطاعتى و رفتارهاى خصمانه نسبت

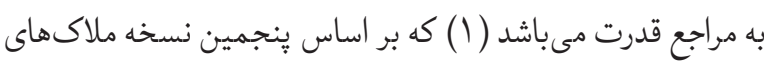

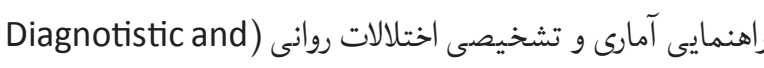
(ه-Statical Manual of Mental Health و بحث،بىاعتنايى، سريّجِى، آزار ديخران خود را نشان مىدهد.

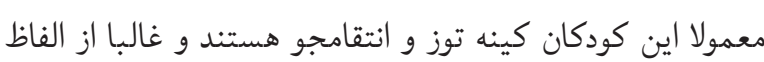

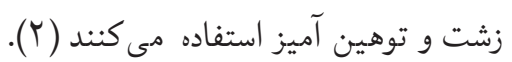

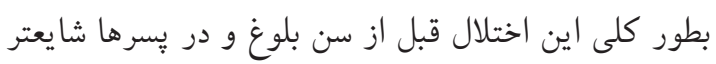

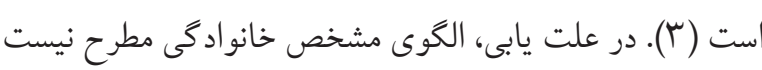
ولى زمانى كه در دوران كودكى والدين فوق العاده سخت كير و

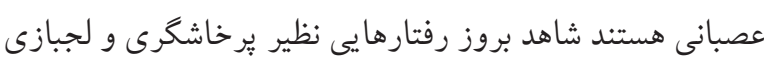

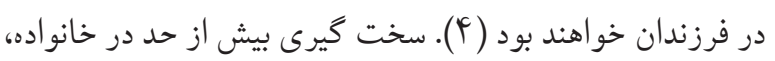

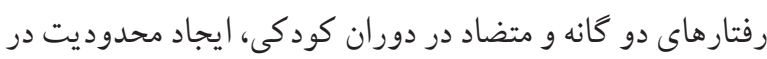

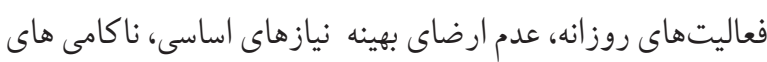

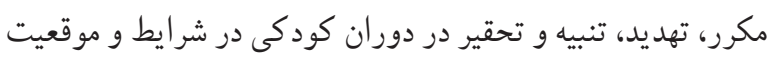

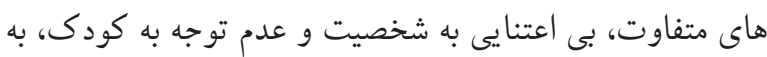

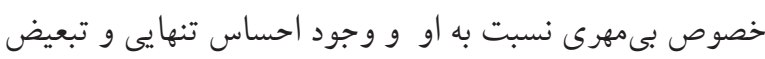
مى تواند موجب تظاهر رفتار بى اعتنايى شود(ه). به نظر مىرسد يكى از مهمترين مولفههاى تاثير گذار در مشكلات

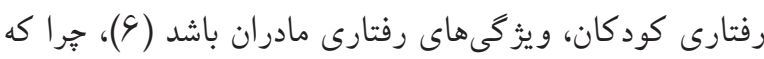

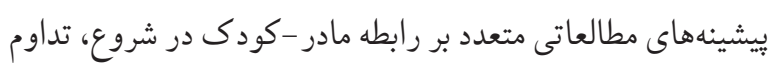

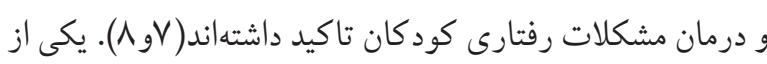

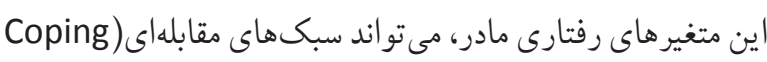

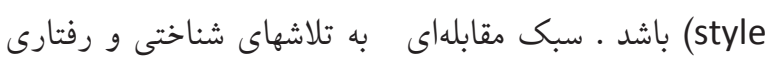

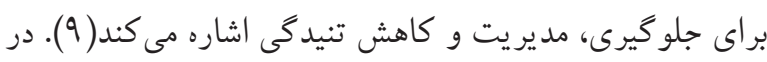

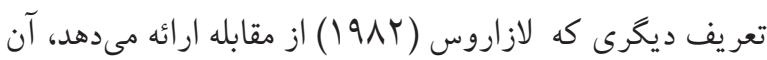
را تلاشهايى معرفى مى كند كه براى مهار (شامل تسلط، تحمل،

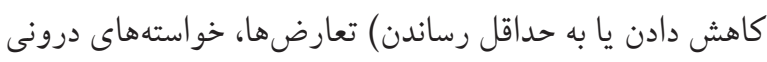
و محيطى صورت مى يذيرد. Higgins, Endler (1990) سبكهاى نداي 
اختلال نافرمانى مقابلهاى بر اساس ينجمين راهنماى تشخيصى و آمارى اختلالهاى روانى شامل نافرمانى و تبعيت نكردن از مقررات

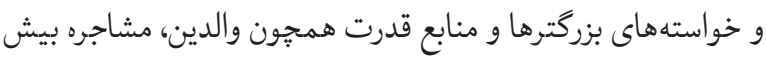
از اندازه با بزركترها و بهويثه والدين، سرزنش كردن و و مقصردانستن فئن

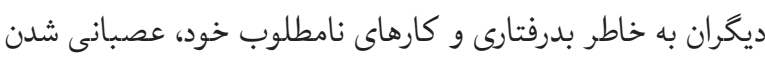
بى دليل در رفتارهاى بينشخصى و كينهجويى (Y) انتخاب شدند.

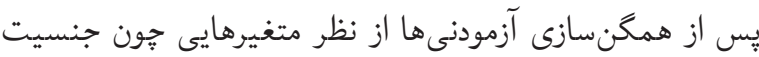

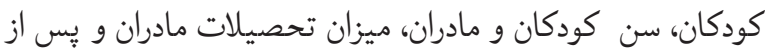

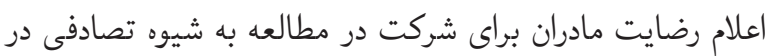

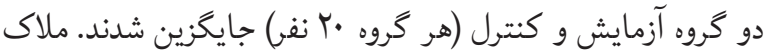
هاى ورود به مطالعه تشخيص اختلال بى اعتنايى مقابله ايى از طريق مصاحبه بالينى و كسب ملاكهاى تشخيصى، عدم داشتن اختلال هاى همراه با استفاده از مصاحبه تشخيصى و يرسشنامه علائم مرضى CSI-4، عدم استفاده از داور درمانى و تحصيلات بالاى دييلم براى مادران براى حضور در جلسات است و عدم شركت بيش از عدم از دو جلسه از معيارهاى خروج بود.

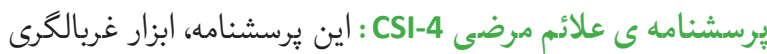

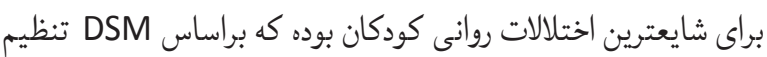

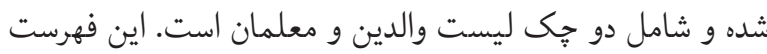

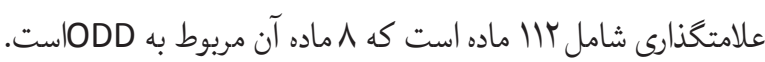
هر عبارت در جَى ليست، در يك مقياس أ درجه اى (هركز، گاهى، اغلب وبيشتر اوقات) پِاسخ داده مى شود ـ محققين مختلف از اين وسيله به عنوان ابزارى مناسب در شناسايى و غربالكرى كودكان مبتلا به ODD ياد مى كنند. در مطالعه اى برووى وץ كودى مبتئلا

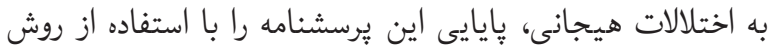

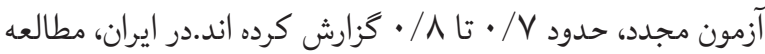

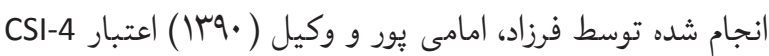

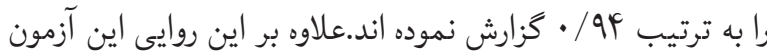
برحسب مطالعات مربوط به روايى محتوا براى سنجش اختلالات روانيزشكى كودكان، مناسب كزارش شده است (YY).

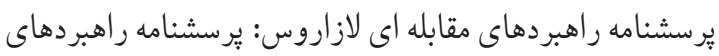

آموزش مهارتهاى زندكى به عنوان برنامه را اولين بار Botvin

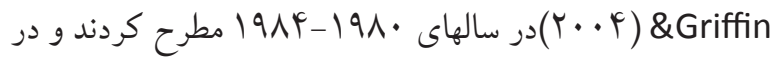

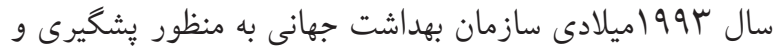
افزايش سطح بهداشت روانى افراد جامعه اين برنامه آموزشى را بها بهان

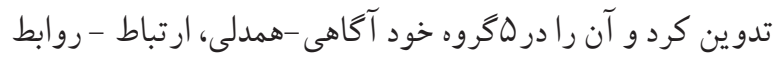
بين فردى، تصميم گيرى-حل مسئله، تفكر خلاق - تفكر انتقادى و مهار كردن هيجانات -مقابله با استرس قرار داد (·r).

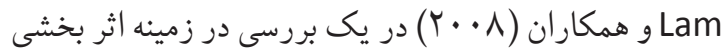

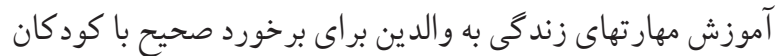

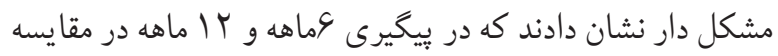

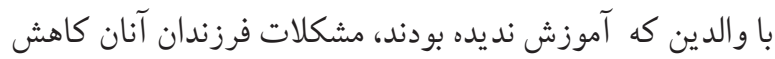

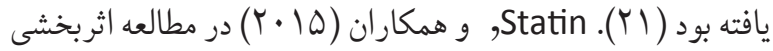
آموزشهاى رفتارى به والدين را بر مشكلات رفتارى كودى مطلوب

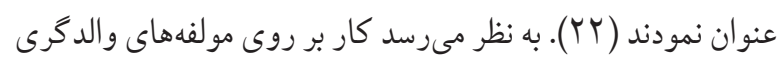

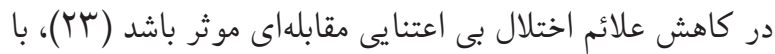
توجه به توصيفات فوق در مطالعه حاضر سعى بر اين است كه

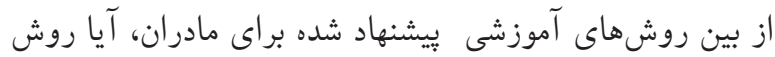

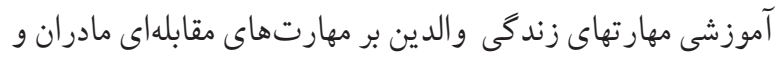

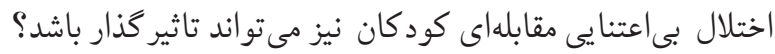

مو اد و روش ها

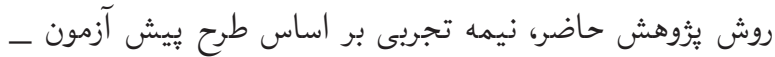

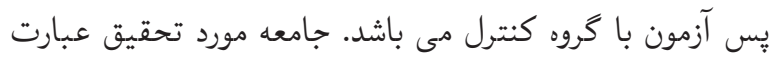

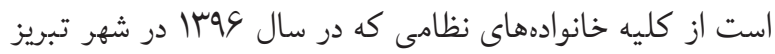

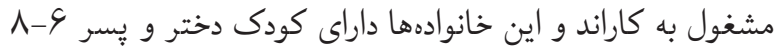

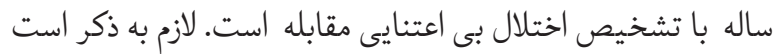
زمان و مكان دقيق نمونه كيرى زمستان و9 از بين مراجع كنندكان

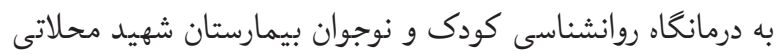
تبريز و درمان زمستان و9 در فرهنگسراى تبريز بود. در اين مطالعه نحوه تشخيص علائم اختلال بى اعتنايى مقابلهاى بر اساس مصاحبه

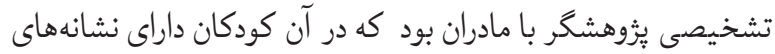


r=به ميزان زيادى از آن استفاده كرده ام) مى باشد.

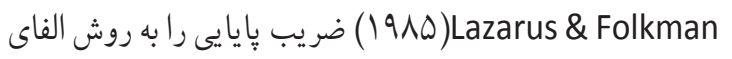

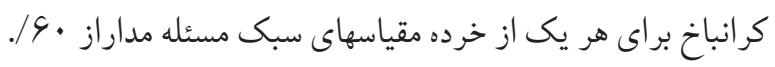

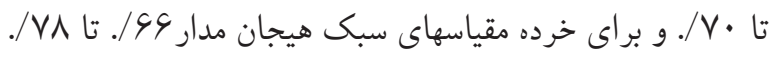

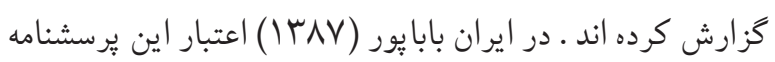

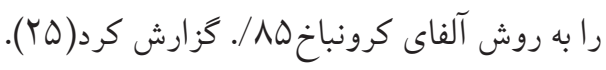

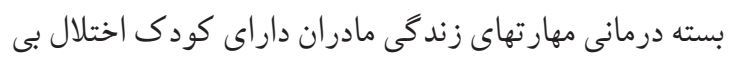

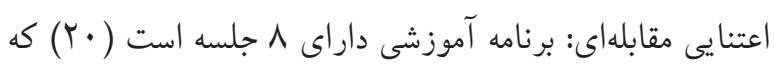

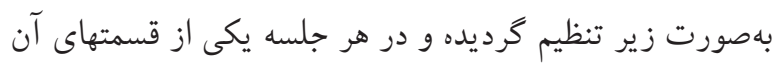
آموزش داده مىشودكه نمونه سر فصل جلسات به شرح زير مى باشد:
مقابله اى يك آزمون 99 وماده اى است كه توسط لازاروس و فولكمن (1910)ساخته شده است و دامنهُ وسيعى از افكار و اعمالى كه

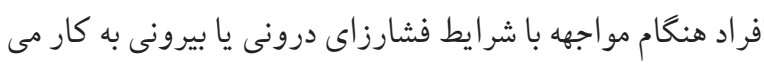

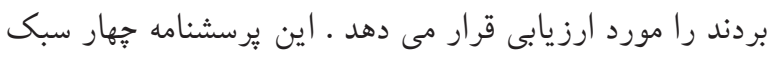

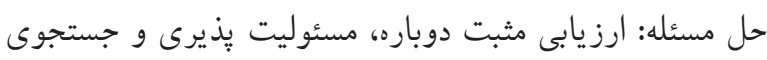

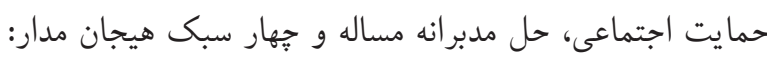
رويارويى مستقيم، خويشتن دارى، اجتنابى و انكار را بررسى مى

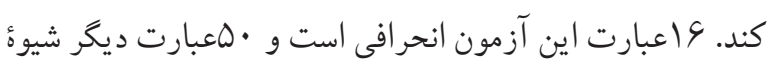

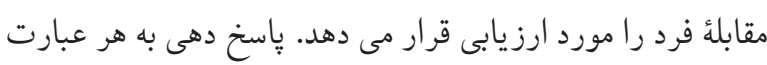

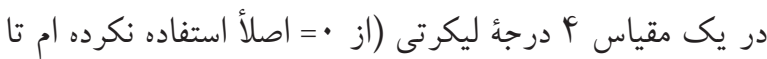

جدول ا : سير جلسات بسته مهارتهاى زندگى

جلسه

آشنايى با اختلال بى اعتنايى آشنايى با سايرشر كت كنندگان- احساس راحتى به عنوان عضو يك گروه-آشنايى با اختلال بى اعتنايى مقابله ای شناخت و راهنى به عنوان عيشخيرى

مقابله

rgl

\begin{tabular}{|c|c|c|}
\hline 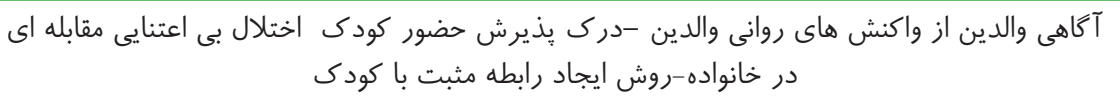 & 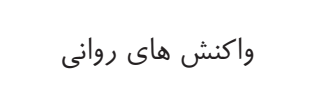 & r \\
\hline آشنايى با شيوه هاى تشويقى و تنبيهى كودكان & 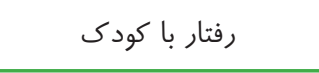 & r \\
\hline فعال نمودن ذهن والدين در رابطه با اهميت مهارت كنترل خشم - آشنايى باخشم و تعريف آن آن آكاهى & 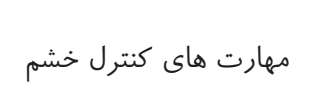 & $\Delta$ \\
\hline 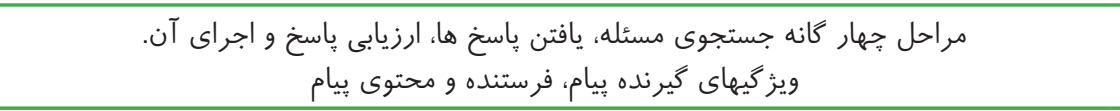 & مهارت حل مسئله و ارتباط & 4 \\
\hline آكاه كردن والدين از احساس خود-ظاهر شدن در نحوه تغيير احساس خود -آشنا كردن والدين با إهيا & 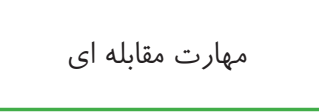 & $\checkmark$ \\
\hline آكاه كردن والدين از ميزان اضطراب و علائم آن-ماهر شدن والدين در كنترل مؤثر اضطراب & مهارت مقابله با اضطراب & $\wedge$ \\
\hline
\end{tabular}

در فرهنگسراى تبر يز بر گزار شد. همجنين براى گروه كنترل نيز

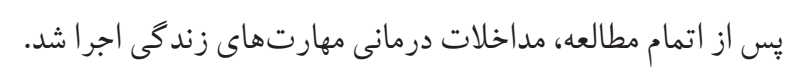

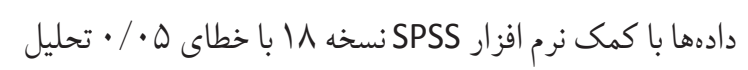

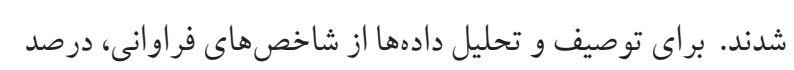

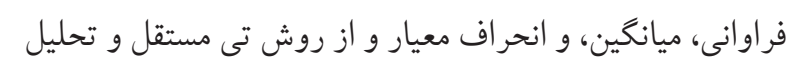

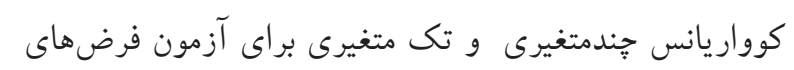
آمارى استفاده شد.
روند اجراى بثزوهش به اين صورت بود كه پِ از دريافت مجوز

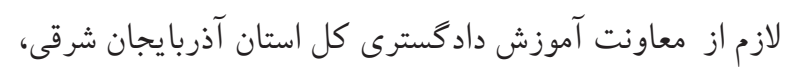

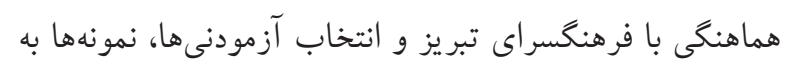

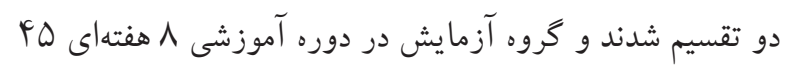

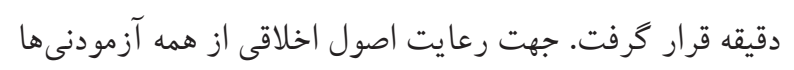

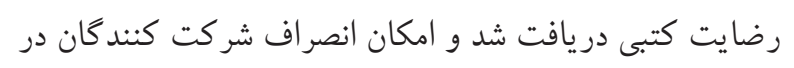

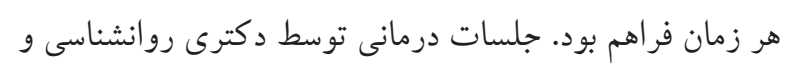




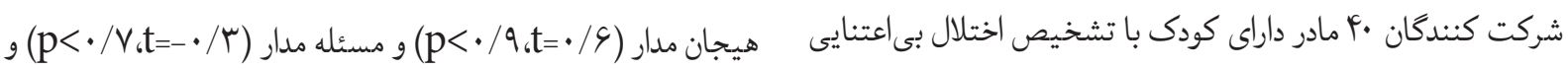

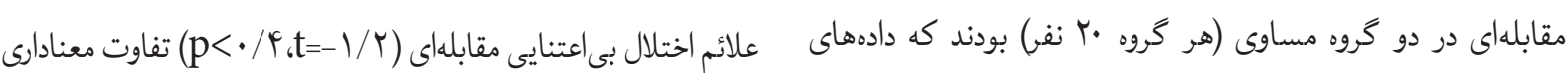

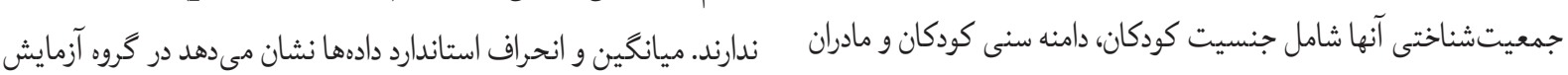
يس از انجام مداخله مهارت هاى مقابلهاى مسئله مدار مادران افزايش و تحصيلات مادران به تفكيك گروه آموزش مهارتهاى زندگى و كنترل

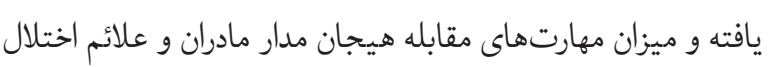
بى اعتنايى مقابلهاى كودكان كاهش يافته است (جدول r). در جدول ب كزارش شده است. نتايج آزمون تى مستقل نشان داد كه

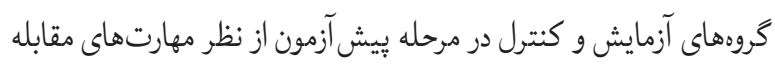
جدول r: ويز گَىهاى جمعيت شناختى گَروه آزمايش و كنترل

\begin{tabular}{|c|c|c|c|c|c|}
\hline \multicolumn{2}{|c|}{ كروه كنترل } & \multicolumn{2}{|c|}{ گروه آموزش مهارتهاى زندگى } & \multirow[t]{2}{*}{ 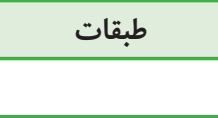 } & \multirow[t]{2}{*}{ ويز كى } \\
\hline درصد & 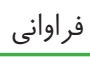 & مر صد & 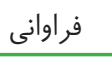 & & \\
\hline Fo & 9 & r. & $\wedge$ & دختر & جنسيت كودكان \\
\hline$\Delta \Delta$ & 11 & G. & Ir & 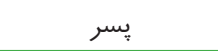 & \\
\hline$\Delta \Delta$ & 11 & $\Delta$. & 1 . & $\checkmark-G$ & دامنه سن كود كان \\
\hline Fo & 9 & $\Delta$. & 1 & $\wedge-\vee$ & \\
\hline$\Delta$. & 1 & s. & Ir & $r \cdot-r \Delta$ & دامنه سنى مادران \\
\hline$\Delta$. & 1. & r. & $\wedge$ & $r \Delta-r$. & \\
\hline$\Delta \Delta$ & 11 & $\Delta$. & 1 & دييلم و فوق ديڤلم & تحصيلات مادران \\
\hline io & 9 & r. & 4 & ليسانس & \\
\hline$\cdot$ & . & $r \cdot$ & r & 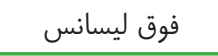 & \\
\hline
\end{tabular}

جدولّا: ميانگين و انحراف استاندارد مهارتهاى مقابلهاى مادران و علائم بى اعتنايى مقابلهاى كودكان گَروههاى آزموش مهارت زندگى و كنترل

\begin{tabular}{|c|c|c|c|c|c|}
\hline \multicolumn{2}{|c|}{ يس آزمون } & \multicolumn{2}{|c|}{ بيش آزمون } & \multirow{2}{*}{ متغير ها } & \multirow{2}{*}{ كروهها } \\
\hline انحراف معيار & ميانگين & انحراف معيار & ميانگين & & \\
\hline $1 / 1$ & $19 / 9$ & $r / \Delta$ & $\mid r / \Lambda$ & ارزيابى مجدد & \multirow{11}{*}{$\frac{1 \cdot \frac{1}{3}}{3 \cdot \frac{3}{3}}$} \\
\hline $1 / \mu$ & $1 \cdot / r \Delta$ & $1 / V$ & $s / F$ & مسئوليت پذيرى & \\
\hline$r / / 1$ & 11 & r & $11 / r \Delta$ & جستجوى حمايت & \\
\hline $1 / 4$ & 19 & r & $1 \cdot / V \Delta$ & حل مدبرانه مساله & \\
\hline$r / \Delta$ & $4 \cdot / 9$ & $\Delta / \mathcal{F}$ & $f \backslash /$ ro & مهارت مسئله مدار & \\
\hline$r / l$ & 1. & $r / \varsigma$ & $1 \mathrm{~V} / 0$ & مواجهه & \\
\hline$r / \Lambda$ & $1 \cdot / \mu$ & $r / \Lambda$ & $19 / 4$ & خويشتن دارى & \\
\hline$r / \mathcal{F}$ & 9 & $r / l$ & $\mid f / \mu$ & اجتناب & \\
\hline$r / 9$ & $1 \cdot / V$ & r & $1 \wedge / \mu$ & انكار & \\
\hline$s / r$ & $r \cdot / \Lambda$ & $V / S$ & $s \varphi / 0$ & مهارت هيجان مدار & \\
\hline $1 / \wedge$ & $11 / r$ & $r / s$ & $19 / 1$ & بى اعتنايى مقابله & \\
\hline
\end{tabular}




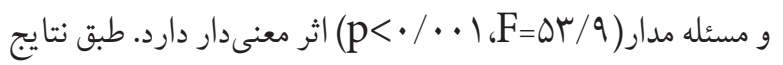
جدول أ، بين كروهها در هر متغير هاى مهار تهاى مقابله هيجان مدار

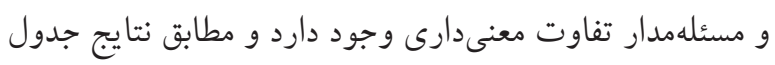

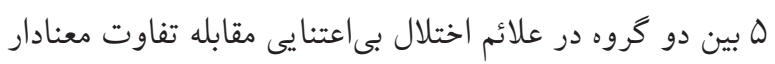

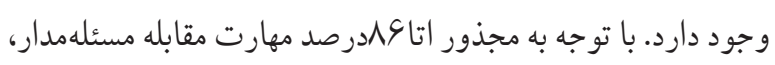

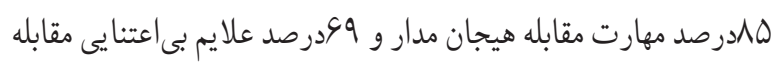

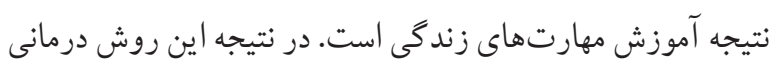

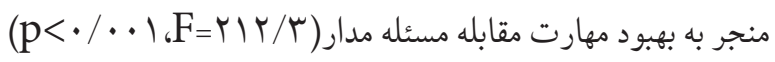

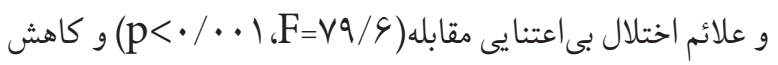

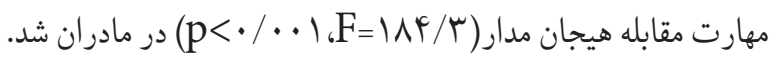

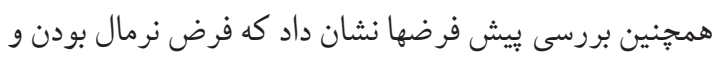

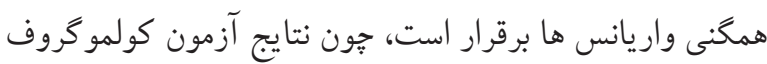

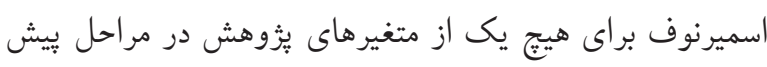

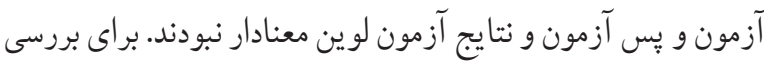

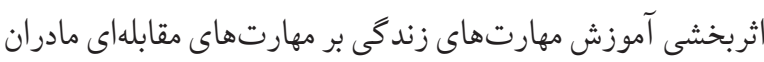

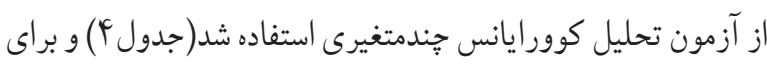

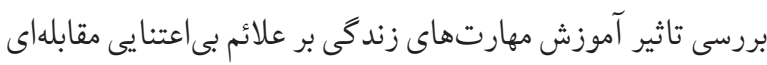

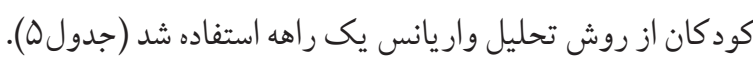

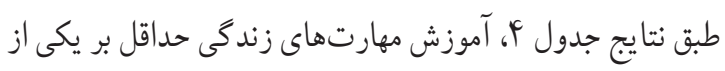

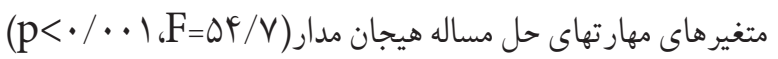

جدول أ نتايج تحليل كوورايانس קند راهه اثربخشى آموزش مهارت زندگى بر مهارت مقابله

\begin{tabular}{|c|c|c|c|c|c|c|}
\hline اندازه اثر & سربع ايتاى & سطح معنادارى & نسبت F & درجات آزادى & مجموع مجذورات & متغير هاى وابسته \\
\hline 1 & $\cdot / \wedge \varsigma$ &.$/ \cdot 1$ & $r \mid r / r$ & 1 & 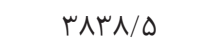 & مهارت مسئله مدار \\
\hline 1 & $\cdot / V$ & $\cdot / \cdots 1$ & $\wedge s / \Lambda$ & 1 & $10 \cdot / 94$ & ارزيابى مجدد \\
\hline 1 & $\cdot / 4$ & $.1 \cdots 1$ & ع/وس & 1 & NG/Or & مسئوليت يذيرى \\
\hline 1 & .14 & $.1 \cdots 1$ & $V \varsigma / V$ & 1 & SFG/OF & جستجوى حمايت \\
\hline 1 & $\cdot / V$ & $\cdot / \cdots 1$ & $\Lambda \Lambda / 1$ & 1 & $r \Delta F / F$ & حل مدبرانه مساله \\
\hline 1 & $\cdot / 10$ & $\cdot / \cdots 1$ & $\mid \wedge F / r$ & 1 & $\Delta \Delta S \Delta / 9$ & مهارت هيجان مدار \\
\hline 1 &.$/ 4$ & $\cdot / \cdots 1$ & $90 / 9$ & 1 & TrG/O & مواجهه \\
\hline 1 & .19 & $\cdot 1 \cdot \cdot 1$ & $\Delta S$ & 1 & 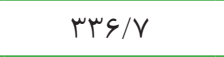 & خويشتن دارى \\
\hline 1 & $\cdot / V$ & $.1 \cdot 1$ & $\vee q / 4$ & 1 & TIr/A & اجتناب \\
\hline 1 & .10 &.$/ \cdots 1$ & rN/q & 1 & 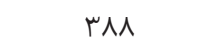 & انكار \\
\hline
\end{tabular}

جدول ه: نتايج تحليل كوورايانس يك راهه اثربخشى آموزش مهارت هاى زندگى بر علايم بى اعتنايى مقابله

\begin{tabular}{|c|c|c|c|c|c|c|}
\hline اندازه اثر & مربع ايتاى سهمى & سطح معنادارى & نسبت F & درجات آزادى & مجموع مجذورات & متغير وابسته \\
\hline$\cdot 19 \wedge$ & $\cdot 199$ & $\cdot / \cdots 1$ & $\vee q / 4$ & 1 & rFN/rr & بى اعتنايى مقابله \\
\hline
\end{tabular}

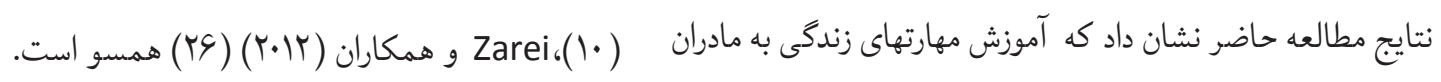

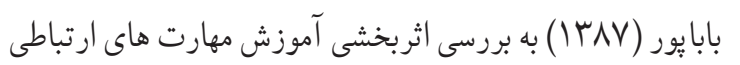

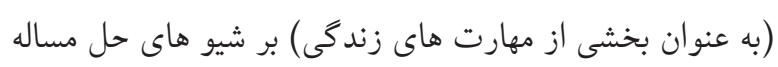

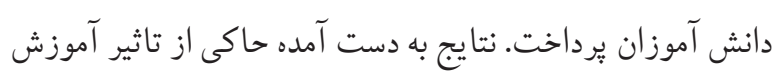

داراى كودك مبتلا به علائم اختلال بى اعتنايى مقابلهاى موجب بهبود مهاد مهارت هاى مقابلهاى مسئله مدار و هيجان مدار مادران شده است.

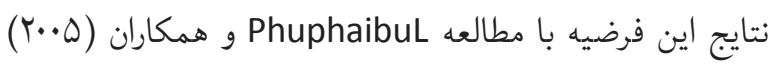


با فرزندشان مواجه شوند.

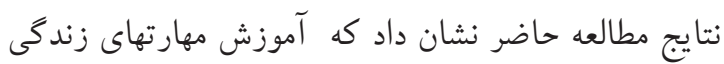
به مادران داراى كودى مبتلا به علائم اختلال بى اعتنايى مقابلهاى موجب كاهش مشكلات رفتارى كودكان مدرسهاى شده است. نتايج

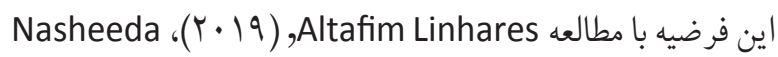

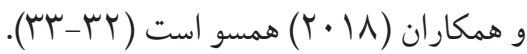
مهارت تنظيم هيجان به عنوان يكى از تو انمندى هايى مهارتهاى

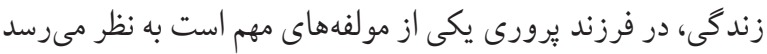

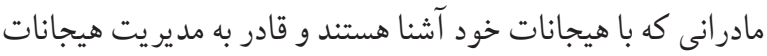

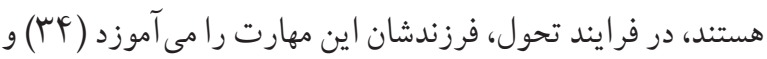
انتظار بر اين است با افزايش مهارت تنظيم هيجان از ميزان مشكلات رفتارى كود كان كاسته شود.

همجنين به نظر مىرسد فر اگيرى مهارت هاى ارتباطى در مادران زمينه مطلوبى براى برقرارى رابطه مثبت با كودى فر اهم مى آورد (19) و در برنامههاى فرزنديرورى مثبت يكى از روشهاى مرئ مناسب كاهش مشكلات لجبازى و يرخاشكرى كود كان ايجاد رابطه مطلوب است (V). مادرى كه مهارت ارتباطى گوش دادن، صحبت كردن

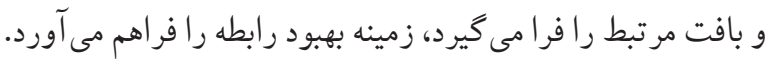

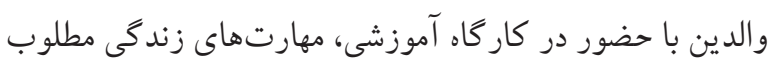
از جمله مهارتهاى حل مسئله، مديريت استرس، كنترل خشم و تعامل با كودى را آموزش مى بينند و همين امر سبب كاهش مشكلات كودى و مشكلات ارتباطى بين والدين و كودى مى شود. در نهايت به نظر مى رسد والدينى كه شرايط كارى نظامى را دارند، با شرايط تربيتى متفاوتى مواجه باشند، شرايط خطير كارى ڤدر و شيفت هايى كه در خانه حضور ندارد بر روابط فرزندان با والدين

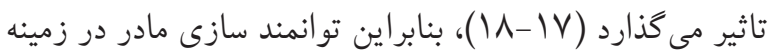
كاهش مشكلات اين خانو ادهها مى تواند مطلوب باشد.

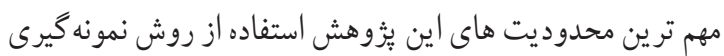

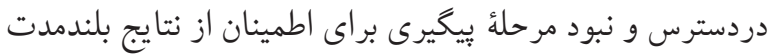

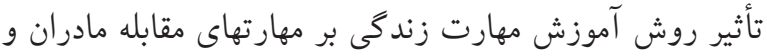

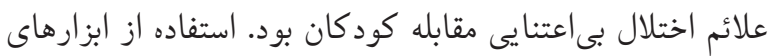

مهارت هاى ارتباطى بر شيوه هاى حل مساله بود (YO). يُزوهش

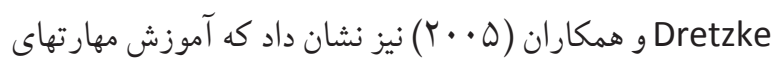
زندگى مىتواند به افزايش مهارت مقابلهاى در برابر استرسهاى

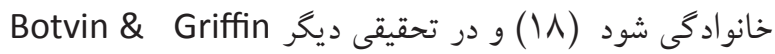

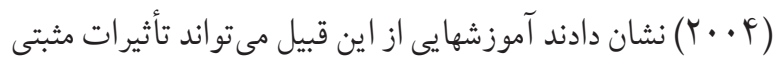
در ارتباطات خانو اده به جا كذاشته و موجب رشد احساساتى از قبيل انسان دوستى در افراد شر كت كننده شود (· • (Y).

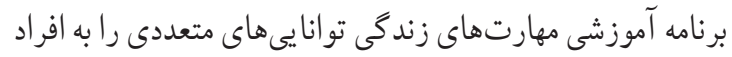
مى آموزد. از جمله اين مهارتها روش كنترل خشم، مهارتهاى تنظيم

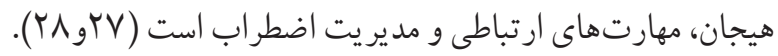

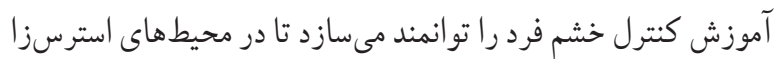
از شيو هایى مقابلهاى مسئلهمدار استفاده نمايد، از طرفى اين شيوه يك تردي

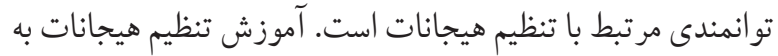

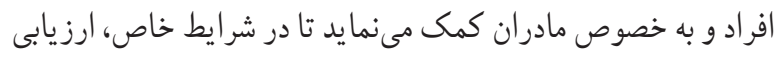
شناختى از شرايط داشته باشند و هيجانات متناسب با موقعيت را مارد بروز دهندو توانمندى خود را در حل مسائل بالا ببرند (9 (Y). به نظر مىرسد فراگيرى مهارتهاى ارتباطى تاثير معنادار در بهبود روابط برد برد

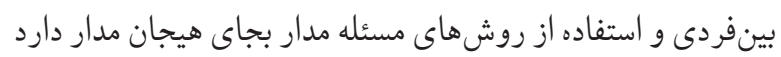

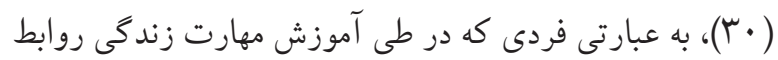
بين فردى مطلوب، روشهاى مختلف ارتباطى را فرامى گيرد، قادر

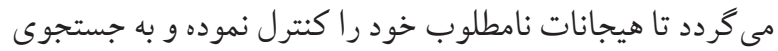
محرك كاى ارتباطى مناسب بيردازد ( آس). مادران حاضر در جلسات مهارتهاى زندكى منى عنوان مي نمودند

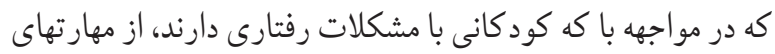
مقابلهاى مناسب برخوردار نيستند و برخى مواقع مشكلات و بحرانها

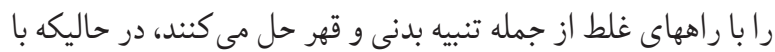

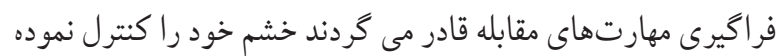

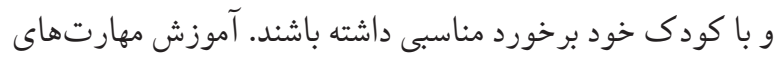
زندگى باعث شد تا مادران روشهاى حل مسئله مطلوب را فر اخيرند و در شرايطى كه فرزندشان رفتار نامطلوبى دارد، از طريق كنترل و

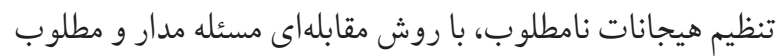


شايعى مىباشد و معمولا روابط والد-فرزند در اين اختلال نقش مهمى دارد. جِرا كه با آموزش مادران در زمينه بهبود مهارتهاى ارتباطى، كنترل خشم، حل مساله كارآمد و نحوه رفتار با كودى از ميزان سبك هاى حل مساله هيجان مدار مادران كاسته شده و بر ميزان سبك هاى حل مساله مسئله مدار آنها افزوده مى كردد و در برابر مشكلات رفتارى، لجبازى و تيرخاشگرى كودكان از روشهاى مطلوبى بهره مى گيرند و منجر به كاهش مشكلات رفتارى در كود كان مىشوند.

تقدير و تشكر: از كاركنان و امور ادارى فرهنگسراى الغدير و همجنين معاونت آموزش داد گسترى كل استان آذربايجان شرقى آنى كه امكان اجراى اين جلسات مداخله را فراهم آورند، تقدير و تشكر مى كردد. تضاد منافع: هيجگگ نه تضاد منافعى در اين مطالعه وجود ندارد.

\section{References}

1-Burke J D, Romano-Verthelyi A R. Developmental pathway to Disruptive, Impulse-Control and Conduct disorder. ACADEMIC press.2018. pp21-25. DOI: https:// doi.org/10.1016/B978-0-12-811323-3.00002-X https://doi.org/10.1016/B978-0-12-811323-3.00002-X PMid:30444635

2- Szentiványi D, Balázs J. Quality of life in children and adolescentswithsymptomsordiagnosisofconductdisorder and oppositional defiant disorder. J Ment Health Prev 2018. 10, 1-8. http://dx.doi.org/10.1016/j.mhp.2018.02.001 https://doi.org/10.1016/j.mhp.2018.02.001

3- López-Villalobos J A, Andrés-De Llano J M, RodríguezMolinero L, Garrido-Redondo M \& Sánchez-Azón M I. Prevalence of oppositional defiant disorder in Spain. Revista de Psiquiatría y Salud Mental (English Edition). 2014. 7(2);80-87. DOI: 10.1016/j.rpsmen.2014.02.006 https://doi.org/10.1016/j.rpsmen.2014.02.006

4- Lin X,Li L, Chi P, Wang Z \& Fang X. Child maltreatment and interpersonal relationship among Chinese children with oppositional defiant disorder. Child Abuse Negl J. 2016; 51: 192-202. http://dx.doi.org/10.1016/j.chiabu.2015.10.013 https://doi.org/10.1016/j.chiabu.2015.10.013 PMid:26560234

5- Lopez Villalobos JA, Sanchez Azon MI. Disruptive behavior disorders: Multidimensional analysis. Int J of Clinic and Health Psych. 2012; 12(3):405-417

6- Gomez R, Hafetz, Gomez R M. oppositional defiant
خودگزارشدهى بخصوص در زمينه تشخيص علايم اختلال بى اعتنايى مقابله و عدم مشاهده بالينى كودكان،براى جمع آورى دادهها محدوديت ديخر بود؛ زيرا ممكن است افراد هنگام تكميل كردن ابزارها خو يشتن نكرى كافى را نداشته باشند و صادقانه ياسخ ندهند. لازم به ذكر است كه در اين بيزوهش تلاش شد با بيان اينكه ياسخ صحيح و غلط وجود ندارد و بهترين پِاسخ، پِاسخى است كه كوياى وضعيت واقعى آنها باشد و اينكه دادهها محرمانه مى مانند و به صورت كلى تحليل مى شوند، از سو گيرى هاى احتمالى كاسته شود. بنابراين بيشنهاد مىشود در بثزوهشهاى بعدى از ييخيرى براى بررسى ثبات يا بى ثباتى نتايج استفاده شود. مشاهده بالينى رفتارهاى كودى و رابطه مادر -كودى انجام گيرد و پيدران شاغل نظامى نيز در جلسات آموزشى مربوطه حضور داشته باشند. نتيجه گيرى: مطالعه حاضر نشان داد ضعف در مهارتهاى زندكى

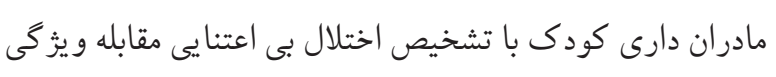

disorder: Prevalence based on parent and teacher ratings of Malaysian primary school children. Asian J Psychiatr. 2013; 6(4):299-302. doi: 10.1016/j.ajp.2013.01.008. https://doi.org/10.1016/j.ajp.2013.01.008 PMid:23810136

7-Brotman L M, O'Neal C R, Huang H Y, Gouley K K, Rosenfelt A, \& Shrout $P$ E. An experimental test of parenting practices as a mediator of early childhood physical aggression. Child Psychol Psychiatry J. 2009; 50(3): 235-245. DOI: 10.1542/peds.2011-1568 https://doi.org/10.1542/peds. $2011-1568$ PMid:22311988 PMCid:PMC3289522

8-Satoorian SA, Ahmad M R. The Role of Parenting Dimensions and Child-Parent Relationship in Children's Internalized and Externalized Behavioral Problem. J Family Research. 2017; 12(4): 683-705

9- Podolski CL, Nigg JT. Parent Stress and Coping in Relation to Child ADHD Severity and Associated Child Disruptive BehaviorProblems.JClinChildPsychol.2001;30(4):503-513. DOI: 10.1207/S15374424JCCP3004_07.PMID:11708238 https://doi.org/10.1207/S15374424JCCP3004_07 PMid:11708238

10- Phuphaibul R, Thanooruk Y. Leucha Y, Sirapo-ngam C. The Impacts of the Immune of Life for Teens Module Application on the Coping Behaviors and Mental Health of Early Adolescents. J Pediatr Nurs. 2005; 20 (6): 461468 . DOI: 10.1016/j.pedn.2005.08.003 PMID:16298288 
https://doi.org/10.1016/j.pedn.2005.08.003 PMid:16298288

11- Lauter J, Branchereau S. Herzog W, Bugaj T J, Nikendei C. Tutor-led teaching of procedural skill in the skilss lab: Complexity, relevance and teaching competence from the medical teacher, tutor and student perspective. J Z Evid Fortbild Qual Gesundhwes. 2017, 122: 5460. doi: 10.1016/j.zefq.2017.03.005 PMID: 28359724 https://doi.org/10.1016/j.zefq.2017.03.005 PMid:28359724

12-Hajiamani Z, Cheragalipour z, Azad Marzabadi E, Ebadi A, Norouzi-koushal A. compression of job srtess in military and non- military drivers in Tehran city. J Mil Med. 2011, 13 (1):25-30

13-Allen Es, Rhoadis GK, Stanley SM, Markman HJ. On the home front: stress for recently deployed army couple. Fam process. 2011; 50(2):235-247. doi: 10.1111/j.1545-5300.2011.01357.x. PMID: 21564063 https://doi.org/10.1111/j.1545-5300.2011.01357.x PMid:21564063 PMCid:PMC4209478

14- Caska CM, Renshaw KD. Perceived burden in spouses of National Guard/Reserve service members deployed during Operations Enduring and Iraqi Freedom. .J Anxiety Disord. 2011Apr;25(3):346-51. doi:10.1016/j.janxdis.2010.10.008 https://doi.org/10.1016/j.janxdis.2010.10.008 PMid:21112182

15- Lacks, Meghan H. An Exploration of Marital Health and Stress Among Military Couples (Master's Thesis, East Carolina University). Retrieved from the Scholarship. (http://hdl.handle.net/10342/1778.).2013

16- Cederbaum J A, Gilreath TD, Astor R A, Pineda D, DePedro $\mathrm{KT}$, Esqueda MC, Atuel $\mathrm{H}$. Well-Being and Suicidal Ideation of Secondary School Students From Military Families. J Adoles Health Volume. 2013; 54( 6): 672677. https://doi.org/10.1016/j.jadohealth.2013.09.006 https://doi.org/10.1016/j.jadohealth.2013.09.006 PMid:24257031

17- Hautmann C, Dose C, Duda-Kirchhof K, Greimel L, Hellmich $M$, Imort \& et al. Behavioral Versus non-behavioral Guided Self-HelpforParentsofChildrenWithExternalizing Disorders in a Randomized Controlled Trial. J Behav Ther; 2018, 49(6): 951-965. https://doi.org/10.1016/j.beth.2018.02.002 https://doi.org/10.1016/j.beth.2018.02.002 PMid:30316493

18-Dretzke J, Frew E, Davenport C, Barlow J, Stewart-Brown S, Sandercock J, Bayliss S, Jeftery J, Hyde C, Taylor R. The effectiveness and cost-effectiveness of parent training/ education programmes for the treatment of conduct disorder, including oppositional defiant disorder. Health Technol Assess. 2005, 1(50), 1-233. doi: 10.3310/hta9500. h tt p s : / / d o i . org/10.3310/ht a 9500 PMid:16336845
19- Daneshmand M. The Effectiveness of Group Training of the Reforming Parenting Styles Based on Mothers, Maladjustment Schemas on Improving Behavioral Problems among Preschool Children in Isfahan City. J Knowledge \& Research in Applied Psychology. 2017, 18 (2):62-71

20- Botvin G J. Griffin K W. Life Skills Training: Empirical Findings and Future Directions. J Prim Prev. 2004; 25(2): 211-232. DOI:10.1023/B:JOPP.0000042391.58573.5b https://doi.org/10.1023/B:JOPP.0000042391.58573.5b

21- Lam K, Wendy S, Fals W, Kelly, M. Effects of parent skills Training with Behavioral couples Therapy for alcoholism on children: A rando mized clinical pilot . J Addict Behav.. 2008; 33: 1076-1081. DOI: 10.1016/j.addbeh.2008.04.002. PMID:18485612 https://doi.org/10.1016/j.addbeh.2008.04.002 PMid:18485612 PMCid:PMC2486258

22- Stattin H, Enebrink P, Özdemir M,\& Giannotta F. A national evaluation of parenting programs in Sweden: The short-term effects using an RCT effectiveness design. Journal of Consulting and Clinical Psychology.2015; 83: 1069-1084. https://doi.org/10.1037/a0039328 https: / / doi.org / 10.1037 / a 0039328 PMid:26009784

23- Tarver J, Daley D, Lockwood J, \& Sayal K. Are self-directed parenting interventions sufficient for externalizing behaviour problems in childhood? A systematic review and meta-analysis. J Eur Child Adolesc Psychiatry. 2014; 23 : 1123-1137. https://doi.org/10.1007/ s00787-014-0556-5 https://doi.org/10.1007/s00787-014-0556-5 PMid:24842197

24-Farzad V, Vakil F, Emami poor S. relaibility and validity of child abnormal psycology symtopms in working child. J Psychological Research. 2012; 11(3):23-30[persian]

25- Babapour KH. Efficacy of interpersonal relationship on problem solving in students. J psychology. 10-8-22

26- Zarei E, SheikhiFini AK, Bavaghar B. Effects of Life Skills Training on Stress Reduction and Coping Style in Adolescents Living in Foster Homes. J Basic Appl Sci Res. 2012; 2(8):7618-7622

27-Kibret B T. Life Skills Training (LST) Program for Young People: Justifications, Foundations and Contents . Int J Sch Cog Psychol.2016;3(1):1-15.DOI:10.4172/2469-9837.1000163 https://doi.org/10.4172/2469-9837.1000163

28- Avci D, Kelleci M. MEffects of the Anger Coping Programme based on cognitive behavioral techniques on adolescents' anger, aggression and psychological symptoms. Int J Nurs Pract, 2016; 22(2), 189-196. https://doi.org/10.1111/ijn.12410 https: / / d o i.org/10.1111/ijn.12410 PMid:26545288

29- Chen C, Li C, Wang H, Ou J J, Zhou J S, Wang X P. Cognitive 
behavioral therapy to reduce overt aggression behavior in Chineseyoungmaleviolentoffenders.JAggressBehav, 2014; 40(4): 329-336. DOI:10.1002/ab.21521. PMID:24375428 h tt p s://doi .org / 10.1002 / a b. 21521 PMid:24375428

30- Högström J, Olofsson V, Özdemir M, Enebrink P, \& Stattin $H$. Two-year findings from a national effectiveness trial: Effectiveness of behavioral and nonbehavioral parenting programs. J Abnorm Child Psychol.2017; 45: 527-542. https://doi.org/10.1007/s10802- 016-0178-0 https://doi.org/10.1007/s10802-016-0178-0 PMid:27334706

31- Meyer S, Raikes H A, Virmani EA, Waters S, \& Thompson R. A. Parent emotion representations and the socialization of emotion regulation in the family. Int J Behav Dev, 2014; 38: 164-173. doi:10.1177/0165025413519014 https://doi.org/10.1177/0165025413519014
32-Altafim E L, Linhares MB. Preventive intervention for strengthening effective parenting practices: A randomized controlled trial. Journal of Applied Developmental Psychology. 2019; 62; 160-172. https://doi.org/10.1016/j.appdev.2019.03.003 https://doi.org/10.1016/j.appdev.2019.03.003

33- Nasheeda A, Abdullah HB, Krauss SE, Ahmed NB. A narrative systematic review of life skills education: effectiveness, research gapsand priorities. IntJAdolescYouth. 2018;2,132138. https://doi.org/10.1080/02673843.2018.1479278 https://doi.org/10.1080/02673843.2018.1479278

34-Rutherford H J V, Wallace N S, Laurent H K, Mayes $L$ C. Emotion regulation in parenthood. Dev Rev, 2015;36: 1-14. doi:10.1016/j.dr.2014.12.008 https://doi.org/10.1016/j.dr.2014.12.008 PMid:26085709 PMCid:PMC4465117 